\title{
NON-CONVENTIONAL BUILDING TECHNOLOGIES AS A PANACEA AGAINST THE COVID-19 PANDEMIC
}

\author{
Bruno Tayo $^{1}$, Jeffrey Mahachi ${ }^{2}$, Benson Wekesa ${ }^{2}$ \\ ${ }^{1}$ Department of Civil Engineering Science, University of Johannesburg \\ PO Box 524, Johannesburg, South Africa \\ 200945847@student.uj.ac.za; jmahachi@uj.ac.za \\ ${ }^{2}$ Department of Civil Engineering Science, University of Johannesburg \\ PO Box 524, Johannesburg, South Africa \\ wekesabw@yahoo.co.uk
}

\begin{abstract}
The impact of the COVID-19 pandemic has shown the lack of adequate housing and infrastructures around the world. The crisis has brought to light the fact that many countries do not have the means to offer adequate treatment medical centres for their population promptly. According to the World Health Organisation (WHO), a COVID patient must be appropriately quarantined or isolated for treatment and this requires a comfortable and safe space to facilitate the speedy recovery of the patient. However, most of the existing hospitals and clinics are built with concrete, timber, and steel (generally referred to as conventional building technologies), which take more time and sometimes costly to construct. Fortunately, other methods can speed up the construction process and also offer an improved environment for the patient and other users in comparison to the conventional building technologies. One such method is known as the non-conventional building technology, also known under various nomenclatures such as Modular Building Systems (MBS), Alternative Building Technologies (ABTs), and Innovative Building Technologies (IBTs). These technologies are available on the market and are generally referred to as Green Building (GB) products. In addition to being environmentally friendly, GB also promotes sustainability and can be used to reduce the lack of housing stock and infrastructure in the community. This article reviews nonconventional building technologies presented by many authors. The adoption of the non-conventional building technologies differs from one country to another, with each country having its standards and procedures to approve the products. As in any technology, there are advantages and disadvantages, but this paper shows that the use of non-conventional building technologies can be used as a panacea to fight against the impact of the COVID - 19 crises.
\end{abstract}

Keywords: COVID-19, Conventional Building Technologies, Non-conventional Building Technologies, Advantages, Disadvantages.

\section{Introduction}

It is recognized that everywhere around the world, governments have invested in substantial healthcare infrastructure development which requires periodic maintenance and renovation. However, there are insufficient resources available to allow renovation and maintenance. For these services to be delivered to the citizens, both in urban and rural areas, it is necessary and important to invest in alternative solutions [1].

With the healthcare system and the capability of hospitals worldwide being overwhelmed, new options are being developed to tackle this issue. Architects and Engineers around the world are taking steps in response to bed shortage and congestion of facilities, in the continuing battle against the impact of the coronavirus [2]. Since it was first detected in January 2020 in the People's Republic of China, the novel coronavirus disease (COVID-19) has spread rapidly throughout the world. In Africa, the main task of tackling the COVID-19 pandemic has been focused primarily on limiting transmission and minimizing disruptions [3]. In light of this, each country has published some regulations to control the pandemic.

Non-conventional building technologies are proposing scalable, easily installed, mobile, and simple frameworks by concentrating their know-how on discovering quick and effective design solutions that can be applied anywhere. Some initiatives are already being introduced and in operation with a very fast execution timeline, while others remain on a conceptual basis, pending acceptance [2]. Consequently, an investment in public health must be a part of each country's effort to build back, an investment for a healthier and safer future. It will not be the last pandemic [4], and the planet must be ready when the next pandemic arrives by finding an alternative construction method. 
Considering sustainable affordable housing for the future, a myriad of construction materials, building techniques, and combinations has been suggested in recent years. The development of housing is often limited by validating materials about new ideas, and processes [5]. Unfortunately, the existing health infrastructures around the world have been using the conventional building technologies method. However, the implementation of innovative technology has presented an opportunity to develop a green building or non-conventional building technologies.

Non-conventional building technologies may appear as a modern construction form, this method of building offsite, shipping, and installing them in half the time as non-conventional techniques have undergone an amazing transformation. The acceptance around the world and in South African communities of such technology and the availability of alternative materials in the country for scaling are among the most important challenges [1], [6].

In South Africa, Agrément South Africa evaluates the fitness for purpose of non-standardised construction products, materials, and systems against performance-based criteria. Performance criteria and test methods are established in consultation with the relevant experts, as required [7]. The durability of the construction materials used and the efficiency of the finished building in terms of health and safety of occupants must be taken into account.

The entire world faces a serious shortage of healthcare infrastructure and there is no exception in South Africa. According to Evans [8], as in China and in other parts of the world, South Africa did not construct new hospitals for the future increase in Covid-19 hospitalization but upgraded existing facilities with non-conventional technologies methods instead. For example, in South Africa, the former Centre and Club House in Pinelands Golf Club has been converted by Old Mutual into the Western Cape Government's 300-bedded quarantine and self-isolation sanitary facility to fight against the COVID-19 pandemic by using non-conventional building technologies[9].

The statistics of the National Institute, of Communicable Diseases in South Africa revealed, about the pandemic in the past few months, that only $8 \%$ of 5571 possible quarantine facilities listed by the Department of Public Works were evaluated by the Health Department. With extremely low facilities in use, they have to comply with standards such as 24-hour surveillance, adequate ventilation, and internet access before the facilities are contracted by the government [10]. Comparatively, the non-conventional building technologies can comply with all the regulations and contribute to the speedy recovery of the COVID-19 patients.

Although the concept of green buildings varies, there is a common conviction that the urban design and construction industry should become more ecological. Many resources, techniques, and innovations must be implemented for the construction of green buildings to respond to this widespread environmental belief.

The purpose of this study is to reveal that, non-conventional building technologies may be one such approach as a panacea against the COVID-19 pandemic in the construction industry. This will contribute and make life relatively easier in the long-term for any future outbreaks and the world will be more ready to face the next pandemics.

A summary of the literature review on the advantages and disadvantages of non-conventional building technologies and the comparative assessment of non-conventional construction technologies and related building systems is given in the following section.

\section{Methodology}

The methodology used in this research paper is Content analysis as shown in Figure 1 below. Content analysis is defined as a scientific analysis of communication content. Content analysis analyses the content of textbooks, posts, newspaper headlines, papers, historical records, lectures, as well as text in the form of photographs, publicity are generally described as informal conversations reflecting the actual event in a language of any communication. The manifest and latent contents of a document may be studied. The observable, countable components of the message are referred to as manifested material [11]-[13].

The analysis and discussion in this paper cope with the use of non-conventional building technologies as a panacea against the COVID-19 in the industry. 


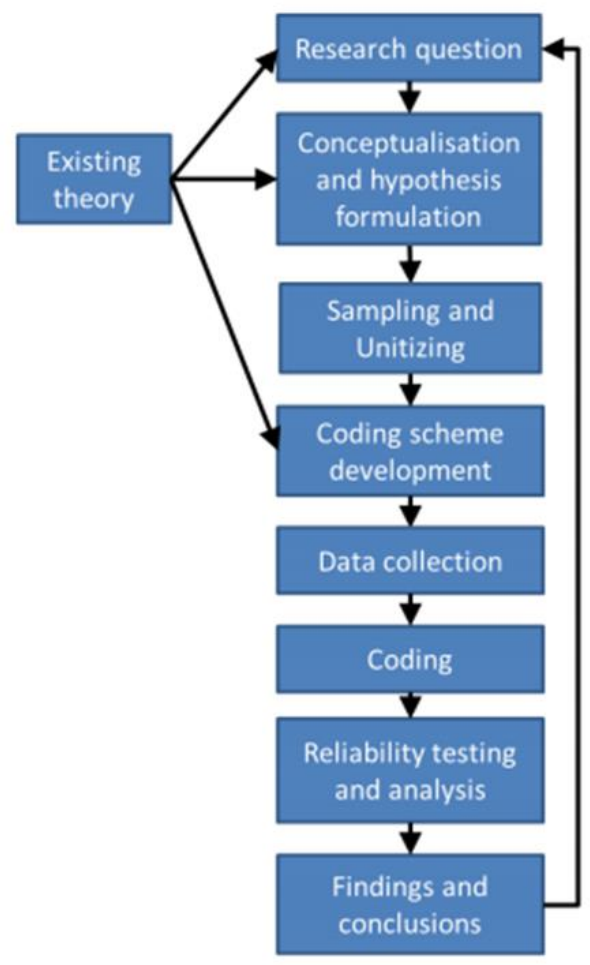

Figure 1: Main steps in the interpretation of quantitative content analysis [13]

\section{Classification of Non-Conventional Building Technologies}

According to Xie and Gou [14], Green Buildings have spread all over the world for the last 30 years, initially starting in the UK, then expanding throughout North America, then West Europe, Singapore, Brazil, Colombia, China, Eastern Europe, and across the whole world in the last ten years. In each nation, a complete ecosystem, consisting of rating systems, training for design and construction professionals, green product creation and system creation, creation of green building consultancies, business case creation for commercial investors, etc., has been required.

Non-conventional building technologies can be identified and classified in several ways, Walling and building systems, often differ based on their various structural components, such as load-bearing wall types, framing systems, and foundation styles. They can be installed on-site or manufactured in the factory and transported to the site. There is a vast amount of literature and documentation on activities around the world, some of which were commonly used from pre-industrial and pre-colonial periods and still serving their users in the right climate.

Also, the smaller assembly systems are based on minor variations, which differ to a lesser degree between nonconventional building technologies and construction methods. Such as the flooring (e.g. wood, concrete, rubberized), the wall details (e.g. insulation, interior finish, exterior finish), and the roofing (e.g. galvanized, tiled, dual-pitch, mono-pitch, flat). There are several minor variations on such structural types in terms of configuration and materials used, as long as it meets the requirements needed [15]. The type of the walling and construction systems can be seen in Figure 2 and 3 and is described as follows: Sandwich Insulated Panels (SIPs), Lightweight Foamed Concrete Building Systems (LFCBS), PVC Building Systems (PVCBS), Container Building Systems (CBS) and Building Blocks Systems (BBS). 


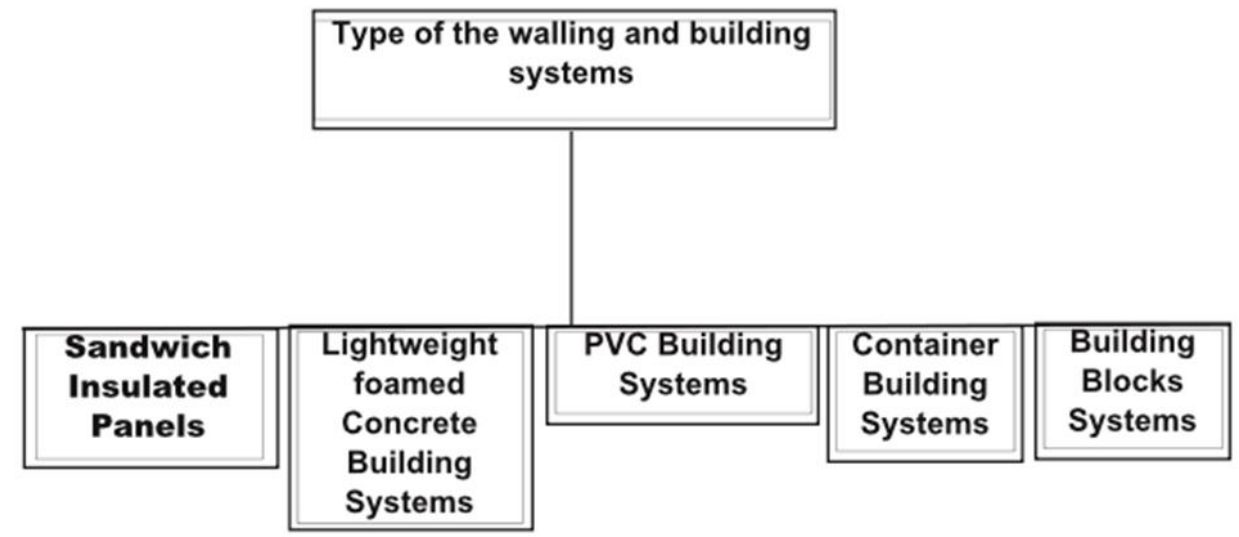

Figure 2.: Type of the walling and building systems

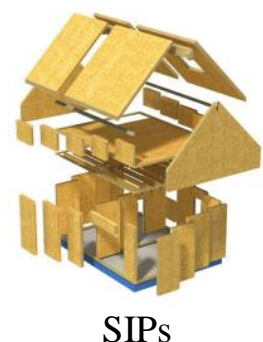

SIPs

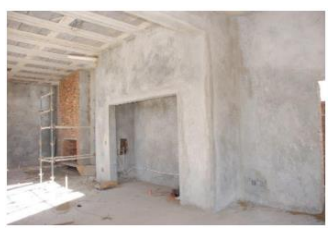

LFCBS

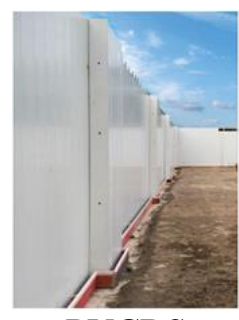

PVCBS

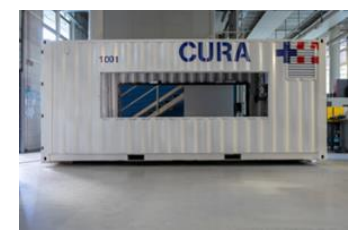

CBS

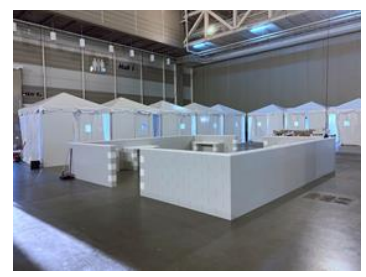

BBS

Figure 3: On-site building systems [16], [17], [18], [19], [20].

\section{Advantages and Disadvantages of Non-Conventional Building Technologies}

The use of non-conventional building technologies is not fully reliant by industry stakeholders and contractors because of issues such as technological challenges, large capital costs, confrontations with the design, and expertise gaps in the building process pose obstacles [21]. Notwithstanding its advantages and disadvantages, the introduction of nonconventional building technologies has been used to address the worldwide housing crisis [22].

\subsection{Advantages}

In the article published by M. N. Hedaoo and S. R. Khese [23], it is explained that Non-conventional building technologies use less power, optimises energy efficiency, conserves natural resources, creates less waste, and offers healthier space for occupants compared to conventional buildings. Non-conventional building technologies reduce the environmental implications of buildings through innovative land use and construction strategies as follows:

Low-cost and added value: Using alternatives building technologies would improve housing distribution, allowing the same number of houses to be constructed at less expense; Innovative technology generates added value by enhancing the product and at times by cutting prices to make it possible for the product to be more widely available on the market [24]. Local content, capacity for development, and local ability to adapt and extend the technology without the assistance of the initial installer [25].

Recycling raw material and environmentally friendly: Greening's advantages including more effective material use and, reduction of final product thermal efficiency. The technology uses fine ash from waste materials. It is then combined to form a rich foam, which is kept jointly by a polymer binder [25], [26].

Effective time and expertise: build-time reductions lead significantly to cost reduction and/or speed of installation (capital and operational). For example, Wuhan Huoshenshan Hospital was completed and delivered after only 10 days of building, and newly diagnosed patients with coronavirus pneumonia were admitted on 3rd February. The basic qualifications needed can be taught on-site quickly [25], [27], [28]. 
Reducing extreme poverty: Development technologies that facilitate jobs creation, work-intensive and skills development and training opportunities are amongst strategies that can foster opportunities for economic growth in urban communities [29]

\subsection{Disadvantages}

Low reputation gain: Partially because the parties involved lack the information and teamwork [22].

Less of flexibility: Panels are not a flexible material as opposed to bricks or blocks. Therefore, the wall has to be cut by a grinder that induces vibrations and breaks in the other walls if the doors or window-frame are to be modified. Panels for construction technology for mounting curtain rails are difficult to penetrate with nails. [24].

Wall width: The wall width is 'too small,' and the material is not ideal for heat management. For fencing or storage, the slabs may be more useful than for the housing. Even before they were assembled and due to vibrations, cracks may appear in alternative construction technology wall panels [24].

Initial cost: Trying to save money on walls using alternative building technologies is always a pointless exercise since walls typically cost less than $10 \%$ of the project's overall costs [30].

Location: Since most of these buildings rely on the sun for energy, they must have the best sun exposure to place them opposite homes[31].

Availability: Particularly in urban areas, where the safety of the environment is not the first choice for citizens, materials for building such structure can be hard to find. Thus, it can cost to ship these materials compared to a normal building[31].

\section{Comparative Assessment of Green Buildings and Conventional Building Technologies}

The key concept is to make the project cost-effectively by cleaning the area where the city is subjected to heavy pollution. The green building strategy maximizes the use of productive building materials and practices. A few strategies and materials for improvement are outlined here as shown in Figure 4 below [32].

Hundreds of sustainable building methods are available worldwide, focusing on different areas of sustainability and constructed for various types of projects[33]. While green building materials and energy-efficient products can cost more and add green premiums to building costs, energy savings as shown in Figure 5, improved home comfort, and lower maintenance costs are what make these additional costs pay for themselves [34]. Energy Star machinery, reliable energy windows and insulation, energy-saving boilers, and regenerative systems raise one-off construction costs but effectively reduce the ownership running and maintenance expenses over future years [34].

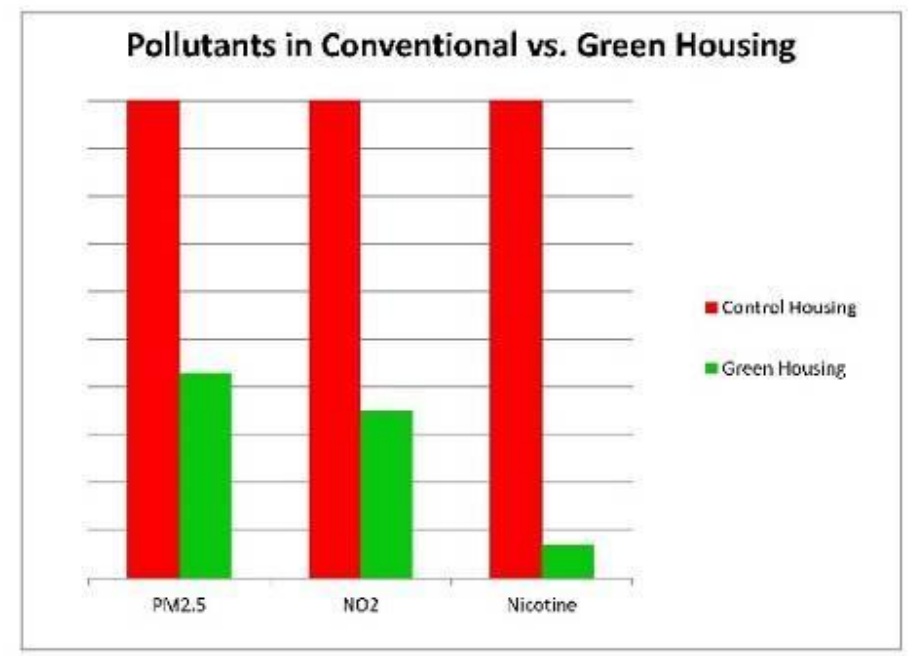

Figure 4: Comparison of green building and conventional building technologies [32]. 


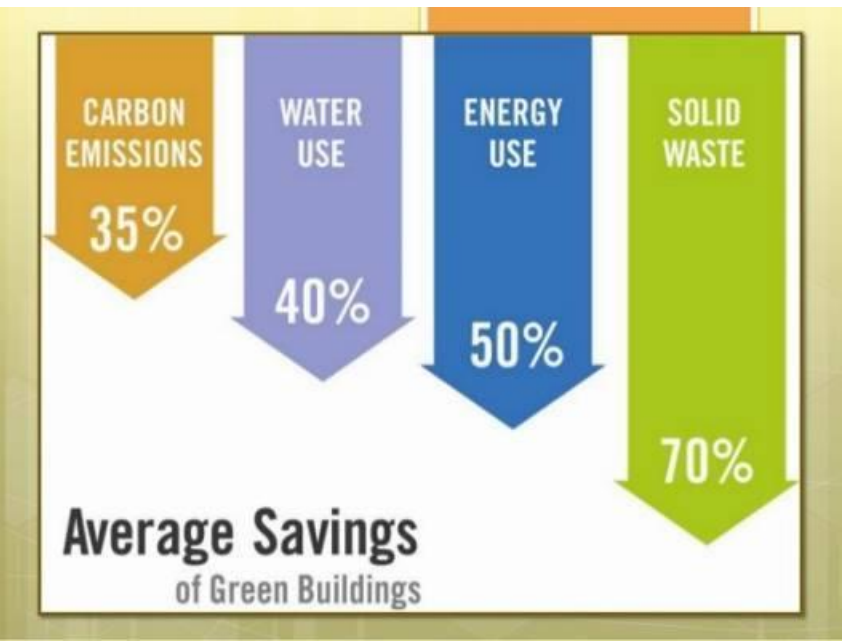

Figure 4: Green construction quality [32], the figure shows the average savings of green buildings.

Also, the primary barrier to the construction of green buildings is initial capital expenditures, Research of this nature is important to understand whether or not green buildings cost more to be constructed. Based in contrast to the modelled cost estimates, and in general, green buildings are not costlier as they supply robust materials and systems. They are known to be more costly in general [35].

Investors in green buildings continue to concentrate on minimizing construction costs without knowing the effect on the economic output of the life cycle. The initial cost of Green buildings tends to be expensive than conventional buildings but the long-term running and maintenance costs are relatively lower. The study conducted by [36] reveals that construction costs are roughly 28 percent higher for green factories than for traditional buildings. However, operating expenses, repair cost, and end of service period costs range from $35 \%$ to $41 \%, 26 \%$ to $30 \%$, and $6 \%$ to $18 \%$ less compared to conventional buildings respectively.

\section{Conclusion}

People still think that a house needs columns and beams plus brickworks to be strong. Conventional building technologies are very slow and expensive in the long-term. A full non-conventional building is better, stronger, cheaper as it can be completed in a matter of days instead of months. It is important to take into account the durability and efficiency of the construction materials used for the health and; the well-being of occupants of the completed structure.

Climate change is real and not a fad, the comparison of green building vs conventional building technologies has shown that the pollution generated by a green building is less than conventional buildings. Green buildings save more energy and use less water, and reduces carbon emissions and solid waste. The adoption of the green building during and after the COVID outbreak should be recommended as the technology is innovative and dynamic. The world must invest, promote, and encourage people in using green buildings as the Chinese government did by constructing a healthcare infrastructure in 10 days.

\section{References}

[1] Human Settlements Republic of South Africa, "Concept Note for Commission 4," no. 6, pp. 6-7, 2017.

[2] C. Harrouk, "Alternative Healthcare Facilities: Architects Mobilize their Creativity in Fight against COVID-19 | ArchDaily," ArchDaily, 2020. https://www.archdaily.com/937840/alternative-healthcare-facilities-architects-mobilizetheir-creativity-in-fight-against-covid-19 (accessed Sep. 10, 2020).

[3] A. U. C. Africa CDC, "Africa Joint Continental Strategy for COVID-19 OUTBREAK," p. 12, 2020.

[4] WHO, "WHO Director-General's opening remarks at the media briefing on COVID-19 - 7 September 2020," Who, 2020. https://www.who.int/dg/speeches/detail/who-director-general-s-opening-remarks-at-the-media-briefing-oncovid-19---7-september-2020 (accessed Sep. 10, 2020).

[5] H. S. Smith, V. Tramontin, and C. Trois, "Assessment of alternative building systems available in South Africa based 
on sustainability indicators," no. July, 2014.

[6] Deluxemodular, "A Brief History of Modular Construction," 2019. https://www.deluxemodular.com/learning-center/abrief-history-of-modular-construction (accessed Sep. 15, 2020).

[7] Agrément South Africa, "Advantages and benefits of Agrément certification," no. October, p. 3708, 2010.

[8] S. Evans, "SA will not build new hospitals China-style, but will use existing state facilities | News24," News24, 2020. https://www.news24.com/news24/SouthAfrica/News/sa-will-not-build-new-hospitals-china-style-but-will-useexisting-state-facilities-20200401 (accessed Sep. 10, 2020).

[9] Old mutual, "Old Mutual converts training facility into COVID-19 quarantine site," old mutual, 2020. https://www.oldmutual.co.za/news/old-mutual-converts-training-facility-into-covid-19-quarantine-site-for-westerncape-provincial-government (accessed Sep. 10, 2020).

[10] A. A. Karim, "South Africa has thousands of potential COVID-19 quarantine hotels. But they're empty. - Bhekisisa," bhekisisa, 2020. https://bhekisisa.org/health-news-south-africa/2020-07-13-south-africa-has-thousands-of-potentialcovid-19-quarantine-hotels-but-theyre-empty/ (accessed Sep. 10, 2020).

[11] C. W. Roberts, “Content Analysis," Int. Encycl. Soc. Behav. Sci. Second Ed., no. 2008, pp. 769-773, 2015, doi: 10.1016/B978-0-08-097086-8.44010-9.

[12] M. Solla, L. H. Ismail, and R. Yunus, "Investigation on the potential of integrating BIM into green building assessment tools," ARPN J. Eng. Appl. Sci., vol. 11, no. 4, pp. 2412-2418, 2016.

[13] M. Kosut and A. M. Bergstrom, "Quantitative Content Analysis," Encycl. Gend. Media, pp. 1-9, 2014, doi: 10.4135/9781452218540.n124.

[14] X. Xie and Z. Gou, Obstacles of Implementing Green Building in Architectural Practices. 2020.

[15] A. W. Botes, "A Feasibility Study of Utilising Shipping Containers To Address the Housing Backlog in South Africa," no. December, 2013.

[16] D. Silvernail, "Introduction to Structural Insulated Panels (SIPs) | SantaCruzArchitect.wordpress.com," 2020. https://santacruzarchitect.wordpress.com/2015/06/30/introduction-to-structural-insulated-panels-sips/ (accessed Sep. 24, 2020).

[17] INDUSTRY NEWS, "Pratliperl insulating and fireproof aggregate," 2020. https://www.b2bcentral.co.za/sustainableplaster-and-screed-for-energy-efficient-buildings/ (accessed Sep. 25, 2020).

[18] Rediwall@, "Permanent PVC Wall Construction Formwork | AFS Formwork," 2020. https://afsformwork.com.au/products/rediwall/construction-process (accessed Sep. 25, 2020).

[19] C. Harrouk, "Gallery of Alternative Healthcare Facilities: Architects Mobilize their Creativity in Fight against COVID19 - 7," 2020. https://www.archdaily.com/937840/alternative-healthcare-facilities-architects-mobilize-their-creativityin-fight-against-covid-19/5e9970aab357652a3c000120-alternative-healthcare-facilities-architects-mobilize-theircreativity-in-fight-against-covid-19-pho (accessed Sep. 24, 2020).

[20] J. Brownfeld, "EverBlock Builds Hospital For 2,000+ Beds For COVID-19 Treatment And Recovery In New Orleans, LA — EverBlock Systems,” 2020. https://www.everblocksystems.com/blog/2020/4/2/everblock-builds-temporaryhospital-for-2000-beds-for-covid-19-treatment-and-recovery-in-new-orleans (accessed Sep. 25, 2020).

[21] B. Hassan and M. Beshara, "Using renewable energy criteria for construction method selection in syrian buildings," Jordan J. Mech. Ind. Eng., vol. 13, no. 2, pp. 125-130, 2019.

[22] W. A. Thanoon, L. W. Peng, M. R. Kadir Abdul, S. M. Jaafar, and M. . Salit, "THE ESSENTIAL CHARACTERISTICS OF INDUSTRIALISED," no. November, 2015.

[23] M. N. Hedaoo and S. R. Khese, “A Comparative Analysis of Rating Systems in Green Building,” pp. 1393-1399, 2016.

[24] South African Cities Network, From Housing to Human Settlements - Evolving Perspectives. 2014.

[25] D. Gardner and J. Pienaar, "Benchmarking Housing Construction Costs Across Africa," no. May, 2019.

[26] M. MOTUMI, “Alternative building technologies to the fore,” 2012. https://www.iol.co.za/the-star/alternative-buildingtechnologies-to-the-fore-1358619 (accessed Apr. 23, 2020).

[27] PropertyWheel, "2013 will be a watershed year for alternative building technologies - Property Wheel," 2013. https://propertywheel.co.za/2013/02/2013-will-be-a-watershed-year-for-alternative-building-technologies/ (accessed Sep. 24, 2020).

[28] H. Miller, "In pictures: China builds two hospitals in days to combat coronavirus," 2020. 
https://www.cnbc.com/2020/01/31/pictures-china-builds-two-hospitals-in-days-to-combat-coronavirus.html (accessed Sep. 25, 2020).

[29] L. Van Wyk, "The efficacy of innovative technologies in subsidised housing in South Africa : A case study," Sci. real Relev. 2010, vol. 3, pp. 1-9, 2010.

[30] N. Riante, "Why alternative building methods aren't feasible in SA yet | Infrastructure news," 2017. https://infrastructurenews.co.za/2017/03/07/why-alternative-building-methods-arent-feasible-in-sa-yet/ (accessed Jun. 07, 2020).

[31] Weetas, "Green Buildings: Advantages and Disadvantages," 2020. https://www.weetas.com/article/green-buildingsadvantages-and-disadvantages/ (accessed Sep. 30, 2020).

[32] V. Ramasamy, "Study on performance of green buildings constructed with special materials STUDY ON PERFORMANCE OF GREEN BUILDINGS," no. December, 2019.

[33] B. K. Nguyen and H. Altan, "Comparative review of five sustainable rating systems," Procedia Eng., vol. 21, no. 0, pp. 376-386, 2011, doi: 10.1016/j.proeng.2011.11.2029.

[34] M. Dillon, "The Costs of Green Vs. Conventional Building | Home Guides | SF Gate," 2020. https://homeguides.sfgate.com/costs-green-vs-conventional-building-80495.html (accessed Sep. 29, 2020).

[35] M. Rehm and R. Ade, "Construction costs comparison between green and conventional office buildings," Build. Res. Inf., vol. 41, no. 2, pp. 198-208, 2013, doi: 10.1080/09613218.2013.769145.

[36] W. Achini Shanika, R. Thanuja, and T. Niraj, "Life cycle cost analysis: Green vs conventional buildings in Sri Lanka," Assoc. Res. Constr. Manag. ARCOM - 33rd Annu. Conf. 2017, Proceeding, no. September, pp. 309-318, 2017. 